\title{
RESPONSABILIDADES EMPRESARIALES DEL TRABAJO EN RÉGIMEN DE SUBCONTRATACIÓN DESDE LA PERSPECTIVA DEL ANÁLISIS ECONÓMICO DEL DERECHO
}

\author{
AdRiana PaLAVECINo CÁCERES ${ }^{*}$ \\ Universidad de Talca
}

\begin{abstract}
RESUMEN. Este artículo analiza los fundamentos doctrinales del agravamiento de la responsabilidad de las empresas principales. Así, aborda el beneficio que reporta al empresario principal la figura de la subcontratación, como también el incentivo frente a un sistema de autocontrol de cumplimiento de la legislación laboral o la teoría del riesgo creado. Asimismo, realiza una crítica al sistema de responsabilidades que establece el Código del Trabajo, desde el punto de vista del análisis económico del derecho, al preguntarse si la nueva asignación de responsabilidades es eficiente en el cumplimiento de la finalidad de lograr una mayor satisfacción individual o social y, particularmente, a si la ley de subcontratación aumenta o disminuye los costos de transacción contractual.
\end{abstract}

Palabras clave: Subcontratación, análisis económico del derecho, responsabilidad solidaria, costos de transacción.

ABSTRACT: This article analyzes the doctrinary fundaments of the hardness of the responsability by the principal companies. Thus, it considerates the profit that the construct of the outsourcing reports to the main businessperson, and also the reward in front of a self-control system of the workforcerelated legislation's abiding or the created risk theory. Acording to this, it makes a critic to the system of responsabilities that the "Código del Trabajo" establishes, from the view of the economic analysis of the law, by asking if the new asignation of responsabilities is efficient in the fulfillment of making a bigger individual or social satisfaction and, particularly, if the outsource law increases or decreases the contract transactions related costs.

Key words: Outsource, economic analysis of the law, solidary responsability, transaction costs.

\section{INTRODUCCIÓN}

Una constatación palmaria es que desde hace décadas la relación laboral paradigmática se difumina, alterándose los elementos esenciales del vínculo de trabajo por los requerimientos del mercado ${ }^{1}$. Se advierte una notoria tendencia a la desconcentración productiva, habida cuenta de procesos o ciclos de producción complejos que ya no son asumidos íntegramente por una única empresa, sino por varias que, actuando coordinadamente, conservan su autonomía económica y jurídica. Una manifestación de este fenómeno es la subcontratación laboral.

\footnotetext{
* Abogada, Universidad de Chile. Profesora conferenciante Facultad de Derecho de la Universidad de Talca.

1 Vid., por todos: HALPERN, Cecily, "Tutela laboral y transformaciones en el mercado del trabajo", en: Actualidad Juridica, Universidad del Desarrollo, año I, No 1, Santiago, enero 2000, passim. CAAMAÑo, Eduardo, "Las transformaciones del trabajo, la crisis de la relación laboral normal y el desarrollo del empleo atípico", en: Revista de Derecho, Universidad Austral de Chile, Facultad de Ciencias Jurídicas y Sociales, vol. XVIII, No 1, Valdivia, junio 2005, passim.
} 
En este trabajo nos proponemos contestar a las siguientes interrogantes: ¿Es eficiente la asignación de recursos o responsabilidades en la Ley No 20.123, sobre régimen jurídico del trabajo subcontratado y del suministro de personal? $\mathrm{O}$ en otras palabras, ¿el agravamiento de la responsabilidad de la empresa principal o mandante respecto de las obligaciones laborales y previsionales de las empresas contratistas y subcontratistas, para con sus trabajadores, generará mayor satisfacción individual o social?

Nuestra respuesta preliminar es que no, y para resolver estas interrogantes, en primer lugar, explicaremos brevemente la forma en que se configura la subcontratación laboral como manifestación de externalización productiva, a través de relaciones contractuales bilaterales, y hacemos mención a algunos datos estadísticos.

Enseguida, analizaremos el agravamiento de la responsabilidad empresarial -de subsidiaria a solidaria- y el modo como el empresario principal puede evitar responder directamente ejerciendo las facultades de información y retención que le franquea la ley.

Reflexionaremos, luego, sobre el problema del fundamento jurídico para este agravamiento de la responsabilidad, para ocuparnos, al final de este trabajo, de dar respuesta a las interrogantes mencionadas, sirviéndonos para ello de algunos postulados construidos por el Análisis Económico del Derecho (AED), y de la capacidad analítica y predictiva de esta metodología.

\section{LA SUBCONTRATACION LABORAL ${ }^{2}$}

La figura de la contratación y subcontratación consiste en que una empresa, denominada empresa principal, encomienda la realización de obras o servicios a una empresa contratista o auxiliar, la que oferta un programa de trabajo con precio, plazos y modalidades de ejecución. Llegado un acuerdo con la empresa principal, el contratista aplica una dotación de trabajadores a la realización de la obra o servicio contratados. En este esquema el contratista es, indudablemente, el empleador de sus trabajadores puesto que es él quien organiza y dirige la mano de obra. La empresa principal recibe un resultado final, sin ejercer un control directo sobre los trabajadores durante el proceso de ejecución.

Esta modalidad de descentralización se enmarca jurídicamente a través de contratos civiles o comerciales firmados entre la empresa principal y las empresas auxiliares ${ }^{3}$. Por su parte, la empresa contratista o auxiliar puede cumplir directamente la obligación contraída con la empresa principal, por el contrato de obra o de servicio, o bien, celebrar un nuevo contrato de la misma especie con otra u otras empresas, para que sean estas las que cumplan por ella la obligación asumida con la empresa principal, las que se denominan subcontratistas. Se forma así una cadena que une a la empresa que encarga la obra o el servicio con la empresa auxiliar-contratista y con la empresa auxiliar-subcontratista. Eventualmente, se podría añadir más eslabones a esta cadena.

\footnotetext{
${ }^{2}$ En esta parte seguimos, en términos generales, a PALAVECINO CACERES, Claudio, Subcontratación. Régimen Jurídico del trabajo subcontratado y del suministro de personal, Editorial Jurídica de Chile, Santiago, 2006, p. 55.

${ }^{3}$ Podría tratarse de contratos de ejecución de obra material, arrendamiento de servicios inmateriales, comisión o mandato mercantil, contrato de transporte, franquicia o engineering.
} 
La Ley 20.123 introdujo al Código del Trabajo el artículo 183-A CT, según el cual,

"es trabajo en régimen de subcontratación, aquél realizado en virtud de un contrato de trabajo por un trabajador para un empleador, denominado contratista o subcontratista, cuando este, en razón de un acuerdo contractual, se encarga de ejecutar obras o servicios, por su cuenta y riesgo y con trabajadores bajo su dependencia, para una tercera persona natural o jurídica dueña de la obra, empresa o faena, denominada la empresa principal, en la que se desarrollan los servicios o ejecutan las obras contratadas".

Entonces, según esta normativa, dos elementos caracterizan la figura:

a) Un contrato de carácter civil o comercial que vincula a una empresa que requiere la ejecución de una obra o servicio, con otra que se obliga a efectuarlo;

b) Uno o varios contratos de trabajo que vinculan a esta última con el o los trabajadores que colaboran en su ejecución.

La subcontratación parece ser un signo de modernidad económica y de competitividad, que permite tener mayor flexibilidad en la gestión de recursos humanos y optimizar la estructura de costos de la empresa, la eficiencia y la productividad. Ello explica que, de acuerdo con los resultados de la Encuesta Laboral del año 20064, de la Dirección del Trabajo, el $41,2 \%$ de las empresas en nuestro país subcontrata actividades a terceros.

Sin embargo, no deja de sorprender que mientras se discutía y aprobaba la reforma a esta figura, se produjera una disminución de la subcontratación que, de acuerdo con la ENCLA 2004, era de 50,5\%. Más adelante reflexionaremos sobre las posibles causas.

PORCENTAJE DE EMPRESAS QUE SUBCONTRATAN ACTIVIDADES A OTRAS EMPRESAS O TERCEROS, DENTRO Y FUERA DEL ESTABLECIMIENTO

\begin{tabular}{|lcccr|}
\hline Tipo de empresa & $\begin{array}{c}\text { Dentro del } \\
\text { establecimiento } \%\end{array}$ & $\begin{array}{c}\text { Fuera del } \\
\text { establecimiento \% }\end{array}$ & No & $\%$ \\
\hline Empresas que subcontratan & 29,4 & 21,7 & 528 & 41,2 \\
Empresas que no subcontratan & 70,6 & 78,3 & 753 & 58,8 \\
Total & 100 & 100 & 1.281 & 100 \\
\hline
\end{tabular}

Fuente: Empleadores, ENCLA 2006.

Por otro lado se observa una directa relación entre el tamaño de la empresa y el porcentaje de servicios u obras subcontratados, de tal forma que a mayor tamaño, mayor subcontratación.

\footnotetext{
${ }^{4}$ En http://www.dt.gob.cl/documentacion/1612/article-95152.html (consultada el 26-7-2008).
} 
PORCENTAJE DE EMPRESAS QUE SUBCONTRATAN, SEGÚN TAMAÑO DE EMPRESA

\begin{tabular}{|lccc|}
\hline Tamaño de empresa & $\begin{array}{c}\text { Empresas que } \\
\text { subcontratan \% }\end{array}$ & $\begin{array}{c}\text { Empresas que } \\
\text { subcontratan \% }\end{array}$ & Total \\
\hline Microempresa & 27,9 & 72,1 & 100 \\
Pequeña empresa & 70,7 & 59,3 & 100 \\
Mediana empresa & 58,7 & 41,3 & 100 \\
Total & 68,3 & 31,7 & 100 \\
\hline
\end{tabular}

Fuente: Empleadores, ENCLA 2006.

\section{LAS RESPONSABILIDADES EMPRESARIALES DEL TRABAJO EN REGIMEN DE SUBCONTRATACIÓN}

Cabe indicar que, de acuerdo con el derogado art. $64 \mathrm{CT}$, la responsabilidad del empresario principal operaba siempre de manera subsidiaria, vale decir, en defecto del cumplimiento del contratista empleador. Si bien se permitía, al igual que ahora, que el trabajador demandara en un mismo proceso al empleador y a los responsables subsidiarios, la ejecución debía dirigirse en primer lugar contra el empleador y solo si su patrimonio resultaba insuficiente para cubrir la totalidad de los créditos del trabajador, podía ejecutarse al responsable subsidiario de grado más inmediato y así sucesivamente. Esto porque el responsable subsidiario es un responsable mediato, que tiene siempre el llamado beneficio de excusión frente al acreedor, quien debe dirigirse previamente contra el patrimonio del inmediatamente obligado.

En efecto, dicho artículo disponía: "El dueño de la obra, empresa o faena será subsidiariamente responsable de las obligaciones laborales y previsionales que afecten a los contratistas a favor de los trabajadores de estos. También responderá de iguales obligaciones que afecten a los subcontratistas, cuando no pudiere hacerse efectiva...".

La Ley 20.123 transformó la responsabilidad del empresario principal en solidaria, en el artículo 183-B CT, inciso primero, según el cual: "La empresa principal será solidariamente responsable de las obligaciones laborales y previsionales de dar que afecten a los contratistas en favor de los trabajadores de estos, incluidas las eventuales indemnizaciones legales que correspondan por término de la relación laboral".

Asimismo, el contratista pasó a ser responsable solidario de las obligaciones laborales y previsionales del subcontratista, pues el inciso segundo agrega que: "En los mismos términos, el contratista será solidariamente responsable de las obligaciones que afecten a sus subcontratistas, a favor de los trabajadores de estos".

Como explica Moraga:

"La responsabilidad solidaria es aquella en la que la empresa principal responde conjuntamente con la empresa contratista en lo adeudado al trabajador. En este 
caso, el empleado puede demandar indistintamente a ambas empresas por el total de sus prestaciones laborales y previsionales, incluidas las indemnizaciones legales" 5 .

Según explica este mismo autor, la responsabilidad del empresario principal respecto de los trabajadores de los subcontratistas continúa siendo subsidiaria, de acuerdo con lo previsto en el inciso $3^{\circ}$ del art. 183-B CT, conforme con el cual: "La empresa principal responderá de iguales obligaciones que afecten a los subcontratistas, cuando no pudiere hacerse efectiva la responsabilidad a que se refiere el inciso siguiente"6. Sin perjuicio de lo expuesto, la responsabilidad de la empresa principal será solidaria o subsidiaria según si ejerció los derechos que la ley le reconoce para controlar el cumplimiento de las obligaciones laborales y previsionales del contratista respecto de sus trabajadores. En efecto, el artículo 183-C CT dispone que: "La empresa principal, cuando así lo solicite, tendrá derecho a ser informada por los contratistas sobre el monto y estado de cumplimiento de las obligaciones laborales y previsionales que a estos corresponden respecto de sus trabajadores, como asimismo de igual tipo de obligaciones que tengan los subcontratistas con sus trabajadores". Por su parte, el artículo 183-D CT indica que: "Si la empresa principal hiciere efectivo el derecho a ser informada [...] responderá SUBSIDIARIAMENTE de aquellas obligaciones laborales y previsionales que afecten a los contratistas y subcontratistas, a favor de los trabajadores de estos...".

De acuerdo con estas normas, el derecho de la empresa principal consiste en:

- El derecho a ser informada por el contratista acerca del monto y estado de cumplimiento de las obligaciones. La forma de acreditar el cumplimiento es a través de: certificado de la Inspección del Trabajo o los medios idóneos que garanticen la veracidad del monto y estado de cumplimiento.

- El derecho a retener las obligaciones que tenga con el contratista o subcontratista.

- El derecho a pagar por subrogación al trabajador o institución previsional acreedora.

De acuerdo con el art. 183-B CT, la responsabilidad de la empresa principal se extiende a las obligaciones de dar o pecuniarias laborales y previsionales, como también a las indemnizaciones legales que correspondan por término de la relación laboral.

Sin embargo, además de las obligaciones explícitas que impuso el legislador laboral al empresario principal, no consideró una serie de obligaciones implícitas como las de orden tributario que se detonan cuando el empresario, en cumplimiento de esta responsabilidad irradiada, debe pagar remuneraciones a trabajadores ajenos ${ }^{7}$.

\footnotetext{
5 Moraga Fritz, Álvaro, "La nueva Ley de Subcontratación", en Revista de Derecho de la Empresa, Universidad Adolfo Ibáñez, No 12 , octubre-diciembre, 2007, pp. 40-41.

${ }^{6}$ Aqui el legislador incurre en un error pues la referencia debió ser al inciso anterior.

7 Palavecino CÁCERes, Claudio, "Efectos tributarios de la subcontratación y del suministro de trabajadores", en: Actualidad Juridica, Universidad del Desarrollo, año IX, Nº 18, Santiago, julio 2008, p. 552.
} 


\section{FUNDAMENTO PARA EL AGRAVAMIENTO DE LA RESPONSABILIDAD}

El agravamiento de la responsabilidad del empresario principal de subsidiaria a solidaria sorprende y plantea el problema del fundamento. ¿Por qué la ley altera el efecto relativo del contrato de trabajo existente entre los trabajadores y el contratista o subcontratista? ¿Qué ocurre con el principio res inter alios acta conforme al cual el contrato solo obliga a las partes que consintieron en él y no a terceros?

Palavecino señala que "la respuesta apremia, porque la Constitución Política garantiza a todas las personas el derecho a la libre contratación y a la libre elección del trabajo (art. $19, \mathrm{~N}^{\circ} 16$ inc. $2^{\circ}, \mathrm{CPR}$ )" ${ }^{8}$. Esta garantía, en términos simples, significa que a nadie puede imponérsele un trabajador o un trabajo. Es evidente que con la nueva normativa se obliga a la empresa principal a hacerse cargo de trabajadores ajenos.

Por otro lado, la Constitución también asegura el derecho a desarrollar cualquier actividad económica lícita (art. 19, No 21 CPR), y la subcontratación lo es, en consecuencia, el empresario que subcontrata tiene derecho a organizar su negocio de la forma que mejor le convenga. Sin embargo, la nueva ley lo pone en una encrucijada: o se transforma en una suerte de inspector del trabajo privado, supervisando que las empresas auxiliares con las que ha contratado cumplan con los derechos laborales de sus trabajadores; o asume directamente la responsabilidad en caso que aquellas no cumplan. ¿Por qué el empresario principal que subcontrata debe asumir un rol fiscalizador que es del Estado? ¿Se condice esto con las garantías constitucionales mencionadas?

Se ha planteado que el fundamento estaría en el beneficio que reporta al empresario principal la actividad laboral de los trabajadores del contratista o subcontratista. La Corte Suprema ha venido sustentando esta posición desde antes de la reforma: “...la responsabilidad legal indirecta que afecta al dueño de la obra o faena tiene su fundamento, por una parte, en el provecho que reporta del trabajo prestado en su interés por los dependientes del contratista y, por la otra, en el imperativo de cautelar el debido cumplimiento de las obligaciones laborales y previsionales que benefician a esos trabajadores..."'.

A propósito del alcance temporal de esta responsabilidad, la Corte Suprema reitera el argumento del beneficio al indicar que:

"no se corresponde con el sentido de justicia hacer responsable al dueño de la obra, empresa o faena de las obligaciones [...] que hayan surgido con anterioridad a su vinculación con el contratista o de este con el subcontratista o con posterioridad a la obra, empresa o faena de que se ha tratado y en cuyo proceso productivo el responsable subsidiario ha obtenido provecho de la fuerza laboral que exige o demanda la concretización de los derechos que la ley, el contrato o la práctica le han

\footnotetext{
${ }^{8}$ Palavecino CACeres, Claudio, op. cit., p. 57.

${ }^{2}$ Revista de Derecho y Jurisprudencia y Gaceta de los Tribunales, Tomo XCVIII, Segunda parte, Sección tercera, julioseptiembre 2001, p. 173.
} 
reconocido. Cabe aplicar aquí un aforismo que resume lo que se ha venido expresando: donde está el beneficio, está la carga"10.

Esta explicación no resulta satisfactoria porque ignora el carácter oneroso conmutativo del contrato de obra o de servicio, pues, a cambio de la actividad laboral de los trabajadores, el empresario principal se obliga a pagar un precio que se mira como equivalente. Queda perfectamente constituido el sinalagma genético del contrato sin necesidad de agregar obligaciones o cargas al empresario principal fuera de pagar un precio justo, por lo tanto, no se vislumbra cómo el argumento del beneficio podría aplicarse.

Por su parte, otros autores como Ugarte, ubican el fundamento en el incentivo a un sistema de autocontrol del cumplimiento de la legislación laboral y en la posición jurídica prevalente del mandante respecto del contratista. En efecto, este autor señala que:

"Se establece una responsabilidad solidaria. La ley establece, como mayor novedad en la materia, un agravamiento de la responsabilidad del mandante, pero no por un hecho del contratista (como sería, por ejemplo, el no pago de las obligaciones laborales), sino por un hecho suyo: debe responder solidariamente por no haber ejercido los derechos de control que la ley le otorga (art.183 D). Si ejerce los derechos de control, el empleador queda en la misma situación actual; responde subsidiariamente, si no los ejerce, su responsabilidad se agrava, respondiendo solidariamente. La justificación de esta norma legal es buscar incentivar el sistema de autocontrol del cumplimiento de la legislación laboral: el mandante ve agravado su grado de responsabilidad de subsidiaria a solidaria por el hecho propio de no ejercer los derechos que la ley le otorga -de información y retención-. Estos derechos van dirigidos, precisamente, a velar por el respeto de los derechos del trabajador en régimen de subcontratación. Es obvio que la posición jurídica prevalente del mandante respecto del contratista, reforzada legalmente por la atribución legal de los derechos de información y retención, justifican plenamente que debe verse agravada su responsabilidad cuando, por su propia falta de diligencia en el ejercicio de esos derechos, el pago de las obligaciones laborales y previsionales se vea en situación de no ser integrado" 11 .

No concordamos con este planteamiento en absoluto. Primero, porque el tráfico jurídico y comercial se da ordinariamente entre sujetos asimétricos. Es lo corriente y no aparece tan obvio que la asimetría entre los sujetos intervinientes en las relaciones jurídico-comerciales sea fuente de obligaciones o genere automáticamente una posición de garante para el sujeto con mayor poder respecto del sujeto más débil.

Segundo, porque subyace a esta postura la noción de culpa in contrahendo o responsabilidad precontractual del empresario principal, quien responderá en forma directa si no

\footnotetext{
${ }^{10}$ Es interesante advertir cómo la Corte Suprema, aplicando un "razonamiento económico no formalizado", en palabras de Alfaro Águila-Real, circunscribe la responsabilidad del empresario principal a la vigencia del contrato de obra o de servicio concertado entre aquel y el contratista, lo que sirvió de fuente material para que la Ley $N^{\circ} 20.123$ recogiera expresamente este alcance temporal en los artículos 183-B y 183-D del C.T. Gaceta Juridica, N ${ }^{\circ} 282$, año 2003, diciembre, p. 259.

11 UGARTE, José Luis, "Sobre relaciones laborales triangulares: La subcontratación y el suministro de trabajadores", en Ius et Praxis, 2006, vol. 12, No 1 , Talca, pp. 11-29.
} 
es lo suficientemente diligente para informarse sobre el comportamiento de su contraparte -el contratista o subcontratista - respecto a las obligaciones laborales y previsionales de sus trabajadores, adoptando para ello las medidas de información y control que le franquea la ley. Pero lo que resulta inexplicable es que aunque sea cuidadoso y tome todas las prevenciones del caso, igualmente responderá en forma subsidiaria.

Por último, las facultades de información y retención que la ley contempla para los empresarios mandantes son verdaderas cargas camufladas como derechos. Pues lo propio de un derecho es que su titular pueda ejercerlo o no, inocuamente. $Y$ es una carga desde la perspectiva económica, pues deben generar estructuras operativas internas para ejercer estos "derechos" de fiscalización, o bien, deberán contratar servicios externos, de compañías especializadas para esto.

Otra explicación que se ha dado es la del riesgo creado, pero ¿por qué la subcontratación ha de mirarse como una situación de riesgo? Magdalena Echeverría del Departamento de Estudios de la Dirección del Trabajo, indica que la subcontratación implica transferir responsabilidades; es frecuente que se externalicen procesos "sucios", riesgosos, de alto esfuerzo físico o contenido manual; y la información sobre riesgos y daños laborales bajo esta figura es una zona crítica, frecuente "terreno de nadie"12.

Sin embargo, la situación de riesgo a que se refieren estas teorías se vincula con estructuras físicas, máquinas, equipamiento industrial. De este modo, se considera al riesgo de empresa como un factor de atribución a los fines de lograr el resarcimiento de las víctimas de los daños producidos por el incremento de las nuevas tecnologías, los cuales se constituyen en imprevisibles o inevitables. En otras palabras, es responsable todo aquel que lleve a cabo una conducta que conlleva el riesgo de un resultado dañoso. Si este resultado se presenta, tendrá que responder patrimonialmente. Pero no parece razonable extender esta noción de riesgo a la celebración de contratos que incluyan la figura de la subcontratación, como una actividad peligrosa per se, tanto más si es lícita y se efectúa sin ánimo de perjudicar a los trabajadores, a diferencia de lo que ocurre con la subcontratación simulada.

\section{PERSPECTIVA DEL ANÁLISIS ECONOMICO DEL DERECHO}

Como vimos, los intentos de justificación jurídica del agravamiento de la responsabilidad son insatisfactorios, lo que hace interesante indagar si existe un fundamento desde la perspectiva del Análisis Económico del Derecho (AED) ${ }^{13}$.

El Análisis Económico del Derecho, también denominado Law and Economics, es una metodología que se aplica a problemas de carácter jurídico, principios y conceptos de orden económico. Como expone Lizama:

\footnotetext{
12 En http:/www.antoniorojas.cl/wp-content/uploads/2007/01/subcontr-mecheverria.pdf, consultada el 21-07-2008.

${ }_{13}$ Como indica Ugarte: “...guste o no, el AED, lejos de ser una moda pasajera, se ha transformado en una de las metodologías dominantes de la escena jurídica moderna, especialmente en el ámbito anglosajón, y su propuesta política no es nada de modesta: como explica Posner, el AED no es sino 'la teoría económica del Derecho', incluido, por supuesto, el orden jurídico laboral", en: UGARTE, José Luis, Análisis Económico del Derecho. El derecho Laboral y sus enemigos, Fundación de Cultura Universitaria, Uruguay, 2001, pp.14-15.
} 
"esta propuesta de estudio interdisciplinar ha establecido una novedosa relación entre el derecho y la economía, en términos de situar al derecho como objeto de estudio desde la perspectivas económica. De este modo, se interpreta y evalúa la norma jurídica desde los presupuestos de la teoría económica y en consecuencia, según la racionalidad económica. Esto es, se produce una reformulación económica del derecho que pone en el centro del análisis del material jurídico, los problemas relativos a la eficiencia, el costo de los instrumentos jurídicos en la persecución de sus fines y de las consecuencias económicas de la intervención del derecho"14.

Entre los postulados económicos del AED destaca fuertemente un concepto fundamental que es el principio de eficiencia.

En efecto, siguiendo a Barcia, la preocupación esencial de la economía consiste en cómo asignar recursos escasos logrando el máximo de satisfacción. De acuerdo con esto, será eficiente la asignación de recursos o responsabilidades que logre una mayor satisfacción individual o social ${ }^{15}$.

Este mismo autor indica que, en materia contractual, la satisfacción se traduce en el objetivo de los contratos: lograr la mejor asignación de recursos, la que genere el máximo de satisfacción o de productividad, es decir, excedentes o máximo beneficio para las partes.

Si revisamos la normativa sobre responsabilidad empresarial en el trabajo bajo régimen de subcontratación, desde el prisma del AED, conforme al principio de eficiencia, podríamos preguntarnos: ¿es eficiente la asignación de recursos o responsabilidades en la ley de subcontratación? $\mathrm{O}$, en otras palabras, ¿el agravamiento de la responsabilidad de subsidiaria a solidaria generará mayor satisfacción individual o social?

Uno de los objetivos de esta reforma fue combatir la subcontratación simulada o suministro ilícito de trabajadores o del contratista fantasma. Dado que los tipos sancionatorios infraccionales del art. $478 \mathrm{CT}^{16}$ (hoy art. $507 \mathrm{CT}$ ) de la subcontratación fraudulenta que contemplaban la solidaridad no resultaron eficaces para la erradicación del fraude contra los trabajadores, atribuyéndose esta ineficacia a los elementos subjetivos del tipo infraccional, entonces, se objetiviza la responsabilidad solidaria desvinculándola del fraude a los

\footnotetext{
${ }^{14}$ LizAma PORTAL, Luis, "El análisis económico del derecho y la ley de accidentes del trabajo y enfermedades profesionales", en: Estudios en homenaje al profesor William Thayer, Sociedad Chilena de Derecho del Trabajo y de la Seguridad Social, Santiago, 1998, p. 145.

15 BARCia, Rodrigo, "Los contratos desde la perspectiva del Análisis Económico del Derecho", en: Ius et Praxis, año 4, No 2, Talca, 1998, pp. 150-151.

${ }^{16} \mathrm{El}$ art. $478 \mathrm{CT}$ luego de la reforma introducida por la Ley $\mathrm{N}^{\circ} 19.250$ sancionaba con multa a beneficio fiscal de 1 a 12 UTM al empleador que dolosamente simulara la contratación de trabajadores a través de terceros, o al que utilizara cualquier subterfugio para ocultar, disfrazar o alterar su individualización o patrimonio, con el objeto de eludir el cumplimiento de las obligaciones laborales y previsionales que establece la ley. La Ley $\mathrm{N}^{\circ} 19.759$ eliminó la expresión "dolosamente" del tipo infraccional del art. 478, inciso $1^{\circ}$ del CT, elevó drásticamente las sanciones de 10 a 150 UTM en el eventó de que la simulación provocara perjuicio a los derechos de los trabajadores; estableció la responsabilidad solidaria entre el empleador real y el simulado, y reemplazó la expresión "objeto" por "resultado". Con la Ley $\mathrm{N}^{\circ} 20.123$, su tenor es el siguiente: "Se sancionará con una multa a beneficio fiscal de 5 a 100 unidades tributarias mensuales, al empleador que simule la contratación de trabajadores a través de terceros, cuyo reclamo se regirá por lo dispuesto en el artículo 474. En este caso, el empleador quedará sujeto al cumplimiento de todas las obligaciones laborales y previsionales y al pago de todas las prestaciones que correspondieren respecto de los trabajadores objetos de la simulación".
} 
Adriana Palavecino Cáceres / Responsabilidades empresariales del trabajo en régimen de subcontratación...

trabajadores (equiparando con ello la subcontratación lícita a la ilícita) ${ }^{17}$. De este modo, podría sostenerse que se hizo más asequible al trabajador la disposición de un nuevo patrimonio para hacer efectivas sus acreencias, sin necesidad de tener que acreditar la intención fraudulenta de la empresa principal para sortear la insolvencia de la empresa contratista.

Sin embargo, una visión más holística y una aproximación positiva del AED nos permiten afirmar que con esta normativa se podría ver afectada en forma importante la actividad económica de las PYME, porque los pocos contratistas o subcontratistas que sobrevivirán serán empresas grandes, de alto patrimonio, que den seguridad a las mandantes de que podrán responder a sus obligaciones con los trabajadores. Por su parte, desde la perspectiva de la empresa principal, se encarecerán sus costos de transacción al dificultar el uso de subcontratistas al punto de que ahora pueden recibir demandas de trabajadores ajenos por motivos que escapan directamente a la esfera de control de la empresa, lo que, indudablemente, va a generar un desincentivo de la actividad empresarial bajo esta figura ${ }^{18}$.

Otro objetivo de la reforma fue promover la contratación directa de los trabajadores a lo cual efectivamente puede resultar funcional la intensificación de responsabilidades y cargas ante la decisión descentralizadora. Si de todos modos la empresa que externaliza determinadas funciones productivas terminará respondiendo por las obligaciones laborales de los trabajadores externos "como si" fuera empleadora pudiera ser razonable económicamente la contratación directa. Con todo, tal forma de enfocar la cuestión devela una concepción patológica y sesgada del fenómeno descentralizador conforme a la cual el único objetivo económico de esta sería la reducción de los costos de mano de obra. No se puede desconocer como motivo relevante a la hora de tomar la decisión descentralizadora la sobreregulación del mercado de trabajo, la cual implica altos costos a las empresas e impone importantes exigencias de tiempo y atención al empresario. Pero tampoco se puede desconocer que los distintos mecanismos de descentralización productiva obedecen normalmente a legítimas razones de especialización y racionalidad organizativa y comercial de las empresas.

Como explica Alfaro Águila-Real siguiendo a Paz-Ares, a propósito de la franquicia, como una forma de descentralización, se trata de "una forma muy eficiente de organizar la empresa cuando hay elementos de la misma que pueden centralizarse porque las economías de escala en su producción son prácticamente inagotables (como

\footnotetext{
${ }^{17}$ A este respecto, aplicando el postulado económico del AED de la curva de demanda negativa, Ugarte explica que: "No es difícil trasladar dicho enfoque al ámbito laboral: las multas administrativas, sanción por excelencia en el derecho laboral, no son más que el precio que el empleador debe pagar por infracción a las normas laborales, de modo tal, que su verdadero efecto disuasivo no está dado por la convicción de estar actuando de manera incorrecta, al menos legalmente hablando, sino por la determinación de si dicho costo es superior al beneficio esperado de incumplir con las normas legales de que se trate. Además, en aquellos casos donde la fiscalización laboral es débil, entonces, la actividad de infringir las normas laborales se abarata, ya que el precio baja como consecuencia de una pena que tiene escasas posibilidades de aplicarse", en: UGARTE, José Luis, Análisis... (n. 13), p. 22.

18 Como observó la Confederación de la Producción y del Comercio en su oportunidad: "El proyecto de ley trasforma todas las responsabilidades actuales, de subsidiarias a solidarias, con toda la gravedad que ello implica. Esto resulta excesivo, ya que la subsidiariedad hoy vigente, constituye una garantía suficiente para el debido respeto y cumplimiento de las obligaciones laborales y previsionales de los trabajadores del contratista y del subcontratista. Además, no debe olvidarse que las empresas mandante, contratista y subcontratista son unidades independientes, por lo que la responsabilidad subsidiaria ya constituye una situación excepcional". En http://www.cpc.cl/pdfs/Proyecto\%20sobre\%20 Subcontrataci\%C3\%B3n.pdf (consultada el 21-7-2008).
} 
ocurre con los derechos de propiedad intelectual, las marcas, el saber hacer, el diseño de nuevos productos, el diseño de los establecimientos o el marketing) y elementos cuya producción no debe centralizarse porque se producen, rápidamente, diseconomías de escala. Tal ocurre, sobre todo, con el control y vigilancia de los empleados y con la proximidad de la clientela. Lo que las empresas franquiciadoras hacen es, precisamente, concentrar la producción de los intangibles en la sociedad franquiciadora y asignar el control de los empleados a la empresa franquiciataria. Haciendo titular residual de los rendimientos que produce cada establecimiento franquiciado a un individuo, se le proporcionan los incentivos para maximizar estos. Como el franquiciatario solo puede influir sobre los ingresos del establecimiento asegurando la calidad del servicio que presta y este depende de la labor de los empleados, el franquiciatario tiene los incentivos adecuados para vigilar y controlar a los empleados de su establecimiento, actividad en la que goza de claras ventajas en términos de coste, respecto de la sede central de la empresa franquiciadora. Es decir, asignar la vigilancia de los empleados al franquiciatario es la solución más eficiente en términos de incentivos y de costes" ${ }^{19}$.

Los procesos productivos se vuelven cada vez más intrincados y complejos, lo cual obliga a las empresas a definir su core business y delegar al exterior la realización de funciones subsidiarias aunque controlando directamente su ejecución. Si bien puede conseguirse el objetivo trazado, en el sentido de un incremento de la contratación directa por parte de las empresas, esto puede significar un desaprovechamiento de los efectos virtuosos de la subcontratación con una merma en la eficiencia de las empresas y una pérdida de competitividad respecto de aquellas que operan en regímenes jurídicos más flexibles o con menos cargas ${ }^{20}$.

Por otra parte, las empresas podrían no seguir el camino de la contratación directa salvo en casos muy excepcionales en que la mano de obra resulte insustituible y optar, en cambio, por una reorganización o reingeniería de sus procesos productivos o una tecnologización de estos a fin de reducir la ocupación de mano de obra encarecida por la legislación. Es decir, no es tan seguro que se consiga por esta vía el objetivo de la contratación directa. Probablemente, las empresas compararán los costos de la contratación directa con los costos de generar estructuras operativas internas o la contratación de servicios externos para hacer frente a las responsabilidades que impone la ley. Dicha comparación se extenderá también a los costos de las otras opciones ya mencionadas, vale decir, una reorganización o reingeniería de sus procesos productivos o una tecnologización.

Y justamente, según Coase, uno de los máximos precursores del AED, el ordenamiento jurídico debe tender a evitar los costos de transacción innecesarios ${ }^{21}$. Entonces, la nueva normativa no estaría cumpliendo con esta finalidad, pues, en cuanto al factor de mercado consistente en la extensión de la inversión que requiere el negocio, podría sostenerse que con esta regulación de la responsabilidad, las empresas extenderán su inversión

\footnotetext{
${ }^{19}$ Alfaro Águila-Real, Jesús, "Los juristas españoles y el Análisis Económico del Derecho", en: Revista InDret, Barcelona, enero, 2007, p. 3.

20 Ello podría explicar que Chile sea cada vez un destino menos propicio para invertir y se prefiera otros países.

${ }^{21}$ Según Ugarte, frente a la pregunta acerca de si es eficiente cierta regulación, "la respuesta según la lógica básica del $\mathrm{AED}$, dependerá de los costos de transacción. Si estos son bajos, esta regulación puede ser considerada eficiente, porque junto con asignar claramente el derecho en juego [...] se permite el acuerdo entre las partes, cuestión clave para que el mercado opere en la búsqueda de la solución más eficiente", en: UGARTE, José Luis, Análisis... (n. 13), p. 55.
} 
Adriana Palavecino Cáceres / Responsabilidades empresariales del trabajo en régimen de subcontratación...

en seguros y/o en asesoría jurídica especializada para ponerse a resguardo de la responsabilidad directa que eventualmente les podría afectar ${ }^{22}$.

El AED también se ocupa de los sistemas de responsabilidad. Según Coase, el Estado debe intervenir cuando los altos costos de transacción impiden a las partes lograr un acuerdo que maximice la riqueza, asignando de modo como lo haría el mercado si no fuera por la presencia de estos costos de transacción, los derechos de propiedad o property rights ${ }^{23}$. En este sentido, cabe indicar que la ley de subcontratación, frente al costo de transacción que implicaba el incumplimiento de las obligaciones laborales y previsionales de las empresas contratistas y subcontratistas (empleadoras) respecto de sus trabajadores, faculta a estos a dirigirse contra el empresario mandante para exigir su cobro, como si fuese deudor directo. Creemos que la asignación de esa responsabilidad no fue la medida más eficiente para sortear los costos de transacción de la normativa derogada, ya que no generará una asignación eficiente de recursos, antes bien, operará como un desincentivo a la contratación bajo esta modalidad, por las razones antes explicadas. Como indica Ugarte "...el diseño de las normas jurídicas no puede ir dirigido solo al cumplimiento de ciertos fines sociales valiosos como, por ejemplo, la protección del trabajador, sino que, además, debe responder a lo que Atienza ha denominado la racionalidad técnica que exige que dichos fines se logren al menor costo posible" ${ }^{24}$.

Así el legislador pudo ofrecer un incentivo tributario como contrapartida a las nuevas cargas que impuso al empresario principal, por ejemplo, en a relación la utilización del gasto. En efecto, si producto de las responsabilidades que le impone la ley laboral, la empresa principal va a responder "como si" fuera empleadora de los trabajadores de sus contratistas, entonces, sería justo que, como cualquier empleador, pudiera también deducir de su renta bruta como gasto necesario para producir la renta: los sueldos, salarios y otras remuneraciones que deba pagar en cumplimiento de dichas obligaciones. Sin embargo, el legislador no contempló un incentivo de esta naturaleza "de manera que, los pagos de remuneraciones a trabajadores ajenos efectuados por las empresas en cumplimiento de la responsabilidad solidaria o subsidiaria que impone la ley 20.123 no configuran gasto a efectos tributarios" 25 .

\footnotetext{
${ }^{22}$ En el Suplemento de Economía y Negocios de El Mercurio, del miércoles 26 de septiembre de 2007, se plantea que las empresas intensivas en mano de obra subcontratada -especialmente agrícolas, forestales, pesqueras y constructoras- verán encarecidos sus costos a través del aumento en el gasto en seguros. Esto, por la ampliación de las coberturas relacionadas con la subcontratación de servicios o personas. Antes de la Ley de Subcontratación, el contratante de la póliza era responsable subsidiariamente ante una demanda civil patronal. Cuando entró en vigencia, pasó a ser solidario, con lo que en el caso de un siniestro, si el contratista no tiene cómo responder por una demanda, la empresa primaria debe correr con el $100 \%$ de los costos. Por esto, la mayoría de los asegurados intensivos en mano de obra están pidiendo que exista una cobertura especialmente destinada a proteger a empleados de contratistas y subcontratistas cubriendo distintos frentes: Uno, que el contratista sea asegurado adicional dentro de la póliza, quedando afecto a las mismas coberturas de la misma. Dos, que bajo la cobertura patronal se consideren los empleados de contratistas y subcontratistas como terceros, y ante un accidente laboral, el contratista o su empleado sea considerado un tercero cualquiera al cual se le causó un daño. Tres, las empresas están pidiendo cubrir los contratantes de pólizas, que son todos aquellos daños que un contratista le provoque a un tercero. En http://www.economiaynegocios.cl/noticias/noticias.asp?id=33699 (consultada el 25-7-2008).

${ }^{23}$ Estos no deben entenderse como derechos de corte patrimonial, sino más bien como derechos de actuación que otorga el Estado a los sujetos, de manera exclusiva, en relación a una cosa o una conducta que tenga incidencia en terceros.

${ }^{24}$ Ugarte, José Luis, Análisis... (n. 13), pp. 64-65.

25 Palavecino CACeres, Claudio, "Efectos tributarios..." (n. 7), p. 550.
} 
¿Qué se puede hacer? Siguiendo a Coase ${ }^{26}$, las partes deberán resolver esta falencia mediante el ejercicio de la autonomía privada en el contrato civil o comercial que las ligue. O bien, serán los tribunales los que deberán resolver estos conflictos evitando que aumenten dichos costos. Particular importancia reviste, a nuestro juicio, que los tribunales, al resolver estos conflictos, tengan especialmente en cuenta la naturaleza recíproca de la responsabilidad considerando cada caso en concreto. Y aquí Coase plantea que conviene, en principio, hacer recaer los perjuicios en la parte que pudo evitarlos a un menor costo, y en la hipótesis de subcontratación será evidentemente el empleador real (contratista o subcontratista) más que la empresa principal.

\section{CONCLUSIONES}

Al principio de este trabajo nos planteamos las interrogantes: ¡es eficiente la asignación de recursos o responsabilidades en la nueva ley de subcontratación?, es decir, nos preguntamos si el agravamiento de la responsabilidad del empresario principal de subsidiaria a solidaria ¿generará mayor satisfacción individual o social? Desde la perspectiva del Análisis Económico del Derecho (AED), hemos podido confirmar nuestra postura preliminar en orden a que esta normativa no es eficiente ni generará mayor bienestar individual ni social, puesto que al haber asignado erróneamente las responsabilidades, provocará un aumento en los costos de transacción de las empresas que han decidido desarrollar su actividad económica externalizando algunas de sus etapas de producción, a través de la figura de la subcontratación.

Como vimos, ni siquiera es tan seguro que la nueva normativa cumpla uno de los objetivos que se trazó, cual fue el de promover la contratación directa de los trabajadores subcontratados, combatiendo la subcontratación simulada. Desde este punto de vista, resulta pertinente citar a Calsamiglia, quien indica que: "El legislador no solo debe preocuparse de la justificación política y ética de las normas, ya que es condición necesaria pero no suficiente de una buena ley. También debe prever cụál va a ser la reacción del ciudadano y no puede suponer que el espíritu del derecho por sí mismo incentiva las conductas de los ciudadanos a la obediencia. Existen otros incentivos, a veces mucho más atractivos, para desviarse del Derecho"27.

Por otro lado, a los costos adicionales que implicará la comunicación de responsabilidades laborales y previsionales previstas por la ley, debe sumarse las obligaciones no explicitadas de naturaleza tributaria difíciles de definir y cumplir desde un punto de vista práctico para las empresas, todo lo cual, bajo la justificación de proteger a los trabajadores, probablemente encarecerá y entrabará la contratación laboral.

Todas estas constataciones nos llevan a concluir que más hubiera valido que el legislador laboral se abstuviera de regular esta irradiación de responsabilidad al empresario principal o mandante, manteniéndola como una responsabilidad subsidiaria, pues solo así

\footnotetext{
${ }^{26}$ COASE, Ronald, "The Federal Comunications Commision", The Journal of Law and Economics, 1959, citado por BARCIA, Rodrigo, op. cit., p. 155.

27 CalSamiglia, A., Racionalidad y eficiencia del Derecho, Fontanara, México, 1993, citado por UgarTe, José Luis, Análisis... (n. 13), p. 65.
} 
Adriana Palavecino Cáceres / Responsabilidades empresariales del trabajo en régimen de subcontratación...

podría haberse logrado un resultado más eficiente desde la perspectiva del $\mathrm{AED}$, evitando el impacto que la nueva normativa podría tener en el crecimiento económico y en el empleo.

Pero cabe preguntarse si ¿Puede pedírsele al Derecho del Trabajo - un ordenamiento históricamente tutelar-, como rama del Derecho Privado que es, no proteger a los trabajadores, absteniéndose de utilizar las normas de Derecho Privado con fines de justicia distributiva para alcanzar así un resultado más eficiente? En otras palabras, ¿cuál es el aporte del AED al Derecho del Trabajo que no implique transformar a este en un simple obstáculo a remover en pos de la maximización de la riqueza?

Una respuesta extremista a estas interrogantes que podría darse es que la metodología del AED resulta incompatible con el Derecho del Trabajo e implica un atentado a sus valores fundamentales. Empero, sería una respuesta de suyo intolerante, pues no solo consideramos que la contribución del AED al Derecho del Trabajo puede traducirse en lograr que sus normas sean técnicamente eficientes, sino que, más bien, implica un aporte radical: una reinvención de esta disciplina jurídica, al punto de "sustituirse el derecho protector por el derecho promotor del trabajo" 28 , que dé paso a la flexibilidad y a la desregulación. Pues como indica Palavecino: "Si se quiere que el Derecho del Trabajo no sea una rémora contra el crecimiento y contra el propio empleo, debe operar un cambio en la lógica que preside esta rama del Derecho, cuya creación como conjunto de normas puramente protectoras debería ceder a una nueva lógica basada en la eficiencia económica frente a las necesidades del mercado" 29 .

\section{BIBLIOGRAFÍA}

Alfaro Águila-Real, Jesús, "Los juristas españoles y el Análisis Económico del Derecho", en: Revista para el análisis del Derecho InDret, Barcelona, enero, 2007, pp. 1-13.

Barcia LeHMAnN, Rodrigo, "Los contratos desde la perspectiva del Análisis Económico del Derecho", en: Ius et Praxis, Universidad de Talca, año 4, No 2, 1998, pp. 149-175.

CAAMAÑo, Eduardo, "Las transformaciones del trabajo, la crisis de la relación laboral normal y el desarrollo del empleo atípico", en: Revista de Derecho, Universidad Austral de Chile, Facultad de Ciencias Jurídicas y Sociales, vol. XVIII, No 1, Valdivia, julio 2005, pp. 25-53.

HALPERN, Cecily, "Tutela laboral y transformaciones en el mercado del trabajo", en: Actualidad Jurídica, Universidad del Desarrollo, año I, No 1, Santiago, enero 2000, pp. 177-182.

LIZAMA PORTAL, Luis, "El análisis económico del derecho y la ley de accidentes del trabajo y enfermedades profesionales", Estudios en homenaje al profesor William Thayer, Sociedad Chilena de Derecho del Trabajo y de la Seguridad Social, Santiago, 1998, pp. 145-161.

Moraga Fritz, Álvaro, "La nueva Ley de Subcontratación", en Revista de Derecho de la Empresa, Universidad Adolfo Ibáñez, No 12, octubre-diciembre, 2007, pp. 37-50.

PALAVECINO CACERES, Claudio, Subcontratación. Régimen Jurídico del trabajo subcontratado y del suministro de personal, Editorial Jurídica de Chile, Santiago, 2006.

\footnotetext{
28 PlA Rodríguez, Américo, "La actual coyuntura del Derecho Laboral", en: Descentralización productiva y nuevas formas Organizativas del Trabajo, X Congreso Nacional de Derecho del Trabajo y de la Seguridad Social, España, 2000, p. 1173, citado por UGarTe, José Luis, Análisis... (n. 13), p. 62.

29 Palavecino CACERES, Claudio, Subcontratación... (n. 2), p. 15.
} 
PalAVECINo CACERES, Claudio, "Efectos tributarios de la subcontratación y del suministro de trabajadores", en: Actualidad Jurídica, Universidad del Desarrollo, año IX, N 18, Santiago, julio 2008, pp. 539-553.

UGARTE CATALDO, José: "Sobre relaciones laborales triangulares: La subcontratación y el suministro de trabajadores", en Ius et Praxis, 2006, vol. 12, No 1, pp. 11-29.

Ugarte CaTaldo, José: Análisis Económico del Derecho. El derecho Laboral y sus enemigos, Fundación de Cultura Universitaria, Uruguay, 2001.

\section{SITIOS WEB CONSULTADOS}

- http://www.dt.gob.cl/documentacion/1612/article-95152.html

- http://www.antoniorojas.cl/wp-content/uploads/2007/01/subcontr-mecheverria.pdf

- http://www.cpc.cl/pdfs/Proyecto\%20sobre\%20Subcontrataci\%C3\%B3n.pdf (consultada el 21 de julio de 2008)

_ http://www.economiaynegocios.cl/noticias/noticias.asp?id=33699 